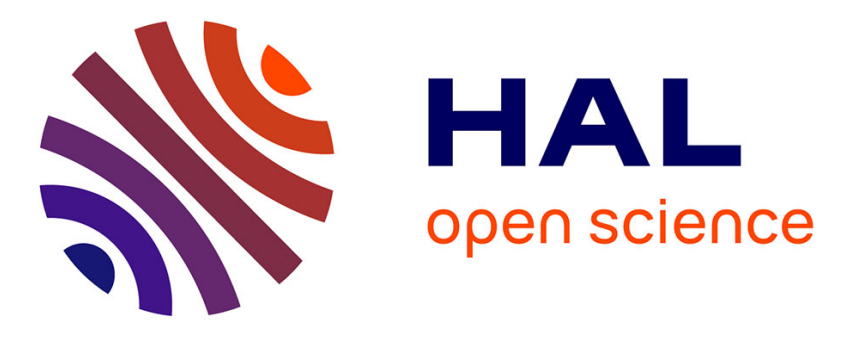

\title{
Copper-Catalyzed Hydroamination of Allenes: from Mechanistic Understanding to Methodology Development
}

\author{
Luca Alessandro Perego, Rémi Blieck, Antoine Groué, Florian Monnier, Marc \\ Taillefer, Ilaria Ciofini, Laurence Grimaud
}

\section{To cite this version:}

Luca Alessandro Perego, Rémi Blieck, Antoine Groué, Florian Monnier, Marc Taillefer, et al.. CopperCatalyzed Hydroamination of Allenes: from Mechanistic Understanding to Methodology Development. ACS Catalysis, 2017, 10.1021/acscatal.7b00911 . hal-01525692

\section{HAL Id: hal-01525692 https://hal.sorbonne-universite.fr/hal-01525692}

Submitted on 22 May 2017

HAL is a multi-disciplinary open access archive for the deposit and dissemination of scientific research documents, whether they are published or not. The documents may come from teaching and research institutions in France or abroad, or from public or private research centers.
L'archive ouverte pluridisciplinaire HAL, est destinée au dépôt et à la diffusion de documents scientifiques de niveau recherche, publiés ou non, émanant des établissements d'enseignement et de recherche français ou étrangers, des laboratoires publics ou privés. 


\begin{abstract}
:
Experimental and theoretical mechanistic studies on the $\mathrm{Cu}(\mathrm{OTf})_{2}$-catalyzed hydroamination reaction of terminal allenes with secondary amines reveal that in-situ generated cationic $\mathrm{Cu}(\mathrm{I})$ is the catalytically active species and explain the observed regio- and stereoselectivity for the unbranched $E$ product. Insight about the structure of the relevant transition states allowed the generalization of this methodology to allenamides and $\mathrm{N}$-allenylcarbamates under unprecedentedly mild and functional group tolerant conditions. Chelation effect by the amide oxygen in addition to electronic effects explain the high innate reactivity of this class of substrates.
\end{abstract}

Keywords: hydroamination, copper, allenes, allenamides, mechanism.

\title{
1. Introduction
}

The development of synthetic protocols that employ easily available starting materials for the construction of valuable compounds is a far-reaching goal of organic chemistry. In this perspective, hydroamination, i.e. the reaction in which an $\mathrm{R}_{2} \mathrm{~N}-\mathrm{H}$ moiety is added across a carbon-carbon double or triple bond, is one of the most desirable transformations to access amines. Indeed, it perfectly fits the requirements of green chemistry, since it has complete atom economy and it does not require the preparation of reactive intermediates such as organic halides or electrophilic nitrogen reagents.

Over the last two decades, an impressive number of protocols have been proposed for the hydroamination of unsaturated compounds, ${ }^{1}$ and most often late transition metals have been revealed the most flexible platform to perform this transformation. . $^{1 \mathrm{n}-1 \mathrm{p}}$ In this context, expensive catalyst featuring precious metals and designer ligands are being more and more frequently replaced by systems based on cheaper metals, ${ }^{1 \mathrm{r}}$ such as iron ${ }^{2}$ and copper. ${ }^{3,4}$

We recently reported an efficient protocol for the $\mathrm{Cu}$-catalyzed regio- and stereoselective intermolecular hydroamination of terminal allenes. ${ }^{3 f, 5}$ Our research efforts aim to gain mechanistic insight useful to support the rational development of new synthetically valuable transformations. In this perspective, we undertook a comprehensive mechanistic study of the aforementioned reaction, using a combined experimental and theoretical approach. ${ }^{6}$

We present here the results of our work, that allowed to shed light on the actual nature of the catalytically active species and to rationalize the observed regio- and stereoselectivity. Mechanistic understanding allowed the extension of the methodology to a new class of substrates - allenamides - under exceptionally mild conditions. 


\section{Results and discussion}

\subsection{Nature of the catalytically active species}

We selected the reaction of phenylallene with morpholine in the presence of $\mathrm{Cu}(\mathrm{OTf})_{2}$ under the conditions previously described by some of us (Scheme 1) as a case of study. ${ }^{3 \mathrm{f}}$

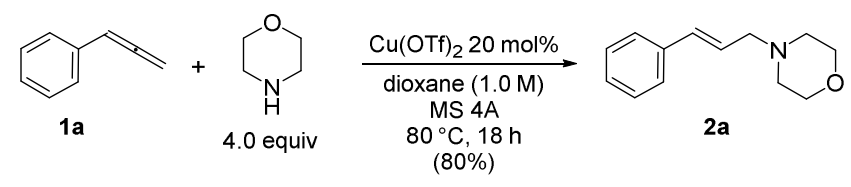

Scheme $1-\mathrm{Cu}(\mathrm{OTf})_{2}$-catalyzed hydroamination of phenylallene. ${ }^{3 \mathrm{f}}$

We analyzed first the nature of the copper species actually present in the solution under catalytically relevant conditions. $\mathrm{Cu}(\mathrm{OTf})_{2}$ is poorly soluble in dioxane, at the ratio used for the hydroamination reaction $\left(0.2 \mathrm{mmol}\right.$ per $\mathrm{mL}$ of solvent) very little of it dissolves at $80{ }^{\circ} \mathrm{C}$ (reaction temperature). When a large excess of morpholine was added ( 20 equiv) at room temperature, this white solid acquired a deep blue color, but the supernatant had only a slight blue tinge. On heating under argon atmosphere at $80{ }^{\circ} \mathrm{C}$ for 10 minutes or after stirring at room temperature for $18 \mathrm{~h}$ all the solid dissolved to give a pale yellow, perfectly homogeneous solution. No line broadening due to paramagnetic species was observed in the no-D ${ }^{1} \mathrm{H}-\mathrm{NMR}$ spectrum of this mixture. $^{7}$

We concluded that the $\mathrm{Cu}(\mathrm{II})$ pre-catalyst employed is reduced to $\mathrm{Cu}(\mathrm{I})$ species in the reaction environment, as it often happens in Cu-catalyzed coupling reactions in which amines are involved. ${ }^{8}$ The reducing agent involved in this process is the amine substrate. It is well-known, indeed, that secondary amines can be oxidized to imines and amidines by $\mathrm{Cu}$ (II) salts. ${ }^{9}$ Anilines, which are also suitable substrates for the hydroamination reaction under study, can also be oxidized by $\mathrm{Cu}$ (II) to a complicated mixture of azocompounds and quinoid condensation products, ${ }^{10}$ also by the intermediacy of radical cations. ${ }^{11}$ The first product of the reduction could be $\mathrm{Cu}(0)$, which is known to further react with $\mathrm{Cu}(\mathrm{OTf})_{2}$ to give $\mathrm{Cu}(\mathrm{I}){ }^{12} \mathrm{The}$ main organic species that is produced by heating a mixture of $\mathrm{Cu}(\mathrm{OTf})_{2}$ with excess morpholine is, indeed, $\mathrm{N}$-formylmorpholine. Further details and a possible pathway for the formation of this compound are given in the Supporting Information (section 1.1).

To further confirm that $\mathrm{Cu}(\mathrm{I})$ species are the actual catalyst of the reaction under study, several $\mathrm{Cu}(\mathrm{I})$ sources were tried instead of $\mathrm{Cu}(\mathrm{OTf})_{2}$ (Table 1). ${ }^{13}$ It resulted that only $\mathrm{Cu}(\mathrm{I})$ salts featuring poorlycoordinating anions ( $\mathrm{TfO}^{-}, \mathrm{PF}_{6}^{-}$) promote efficiently this reaction; interestingly, $\mathrm{CuSO}_{4}$ is completely inactive and apparently it is not reduced under the reaction conditions.

Table 1 - Screening of $\mathrm{Cu}$ precatalysts for the hydroamination of phenylallene. ${ }^{13}$

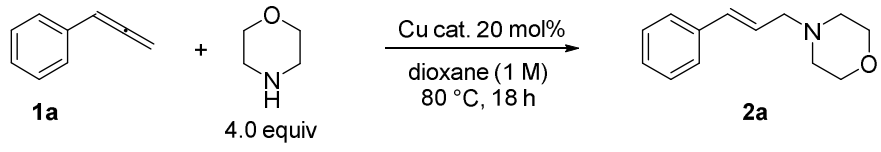

\begin{tabular}{|l|l|l|l|}
\hline Entry & Cat. & Unconverted 1a $^{\text {a }}$ & Yield (\%) $^{\text {a }}$ \\
\hline 1 & $\mathrm{Cu}(\mathrm{OTf})_{2}$ & - & 80 \\
\hline 2 & $\mathrm{Cu}(\mathrm{OTf})_{2}$ & 35 & $8{ }^{\mathrm{b}}$ \\
\hline 3 & $\mathrm{CuOTf} \cdot$ benzene $_{4}(\mathrm{OTf})$ & - & 59 \\
\hline 4 & $\mathrm{Cu}(\mathrm{NCMe})_{4}{ }_{4}$ & - & 78 \\
\hline 5 & $\mathrm{Cu}\left(\mathrm{NCMe}{ }_{4}{ }_{6}\right.$ & - & 52 \\
\hline 6 & $\mathrm{CuSO}_{4}$ & - & 0 \\
\hline 7 & $\mathrm{CuBr}$ & 15 & 11 \\
\hline 8 & $\mathrm{CuBr} \cdot \mathrm{LiBr}$ & - & 14 \\
\hline
\end{tabular}

2 
a
${ }^{b}$ Retermined by ${ }^{1} \mathrm{H}-\mathrm{NMR}$ with $1,3,5$-trimethoxybenzene as an internal standard.

It is well known that cationic $\mathrm{Cu}(\mathrm{I})$, and especially $\mathrm{Cu}(\mathrm{OTf})$, has a good affinity for unsaturated compounds, such as olefins and arenes. ${ }^{14}$ Several studies have been reported on the complexation of allenes with late-transition metals, ${ }^{15}$ such as $\mathrm{Rh},{ }^{16} \mathrm{Pt},{ }^{17}$ and $\mathrm{Ag},{ }^{18}$ but very little is known about $\mathrm{Cu}(\mathrm{I}) /$ allene complexes. ${ }^{18 \mathrm{a}}$ Thus, we studied this system by ${ }^{1} \mathrm{H}$ NMR spectroscopy. The addition of $\mathrm{Cu}(\mathrm{NCMe})_{4} \mathrm{PF}_{6}$ to a solution of allene in DMSO- $d_{6}$ causes an upfield shift of the allene proton resonances, as expected for a fast complexation equilibrium on the NMR timescale. A fixed amount of $\mathrm{Cu}(\mathrm{NCMe})_{4} \mathrm{PF}_{6}$ was titrated with increasing amounts of allenes. The chemical shifts so obtained fitted the equation expected for the formation of a 1:1 complex and data treatment (see the Supporting Information, section 1.2 for the details) gave access to its thermodynamic dissociation constant $K_{\mathrm{D}}$ and to the variation of the chemical shift upon coordination $\Delta \delta\left(\Delta \delta=\delta_{\mathrm{B}}-\delta_{\mathrm{F}}\right.$, in which $\delta_{\mathrm{B}}$ and $\delta_{\mathrm{F}}$ are respectively the chemical shift for the Cu-bound and the free, uncoordinated allene). Data for representative allenes are summarized in Table 2.

Table 2 - ${ }^{1} \mathrm{H}-\mathrm{NMR}$ data for the formation of complexes between allenes and $\mathrm{Cu}(\mathrm{NCMe}){ }_{4} \mathrm{PF}_{6}$ in DMSO- $d_{6}$ at $25^{\circ} \mathrm{C}$ (see the Supporting Information, section 1.2 for detailed data treatment).

\begin{tabular}{|c|c|c|c|c|c|c|}
\hline Entry & Allene & $\delta_{\mathrm{F}}\left(\mathrm{H}^{\alpha}\right)^{\mathrm{a}}$ & $\Delta \delta\left(\mathrm{H}^{\alpha}\right)^{\mathrm{a}, \mathrm{b}}$ & $\delta_{\mathrm{F}}\left(\mathrm{H}^{\gamma}\right)^{\mathrm{a}}$ & $\Delta \delta\left(\mathrm{H}^{\gamma}\right)^{\mathrm{a}, \mathrm{b}}$ & $K_{\mathrm{D}}{ }^{\mathrm{b}}$ \\
\hline 1 & & 6.359 & $-0.047 \pm 0.002$ & 5.280 & $-0.397 \pm 0.017$ & $(37 \pm 4) \mathrm{mM}$ \\
\hline 2 & & 7.020 & $-0.156 \pm 0.003$ & 5.558 & $-0.806 \pm 0.013$ & $(0.65 \pm 0.13) \mathrm{mM}$ \\
\hline 3 & & 5.293 & $-0.398 \pm 0.008$ & - & - & $(4.9 \pm 0.6) \mathrm{mM}$ \\
\hline
\end{tabular}

${ }^{a}$ Chemical shifts are given in ppm with reference to internal TMS. ${ }^{b}$ Asymptotic standard errors of the fitting procedure are given as uncertainties.

As for the vast majority of metal-olefin complexes, coordination causes an upfield chemical shift (all the $\Delta \delta$ are negative). This is an indication that the metal-allene bond has an important $\pi$-backbonding character in the framework of the Dewar-Chatt-Duncanson model, i.e. electron density is donated by the metal center to the $\pi^{*}$ antibonding orbital of the unsaturated compound. The magnitude of this phenomenon is enough to compensate the opposite effect induced by ligand-to-metal $\sigma$-bonding. ${ }^{14 b-c}$

In the presence of the amine nucleophile, displacement of the allene from copper could take place. In order to have a rough estimate of this effect, a mixture of 1 and $\mathrm{Cu}(\mathrm{NCMe})_{4} \mathrm{PF}_{6}$ in DMSO was titrated with increasing amounts of morpholine $(\mathrm{mp})$ and the displacement of the allene from the complex with $\mathrm{Cu}(\mathrm{I})$ was followed by ${ }^{1} \mathrm{H}$ NMR spectroscopy. Data treatment (see the Supporting Information, section 1.3 for the details) allowed evaluating the thermodynamic constant $K_{S}$ for the ligand substitution reaction (Scheme 2). The values found $\left(K_{\mathrm{S}}=19\right.$ for $\mathbf{1 a}$ and $K_{\mathrm{S}}=0.63$ for $\left.\mathbf{1 b}\right)$ are such that under catalytically relevant conditions (excess amine with respect to the catalytic amount of copper) there is competition between the two substrates of the reaction for binding $\mathrm{Cu}(\mathrm{I}){ }^{19}$ 


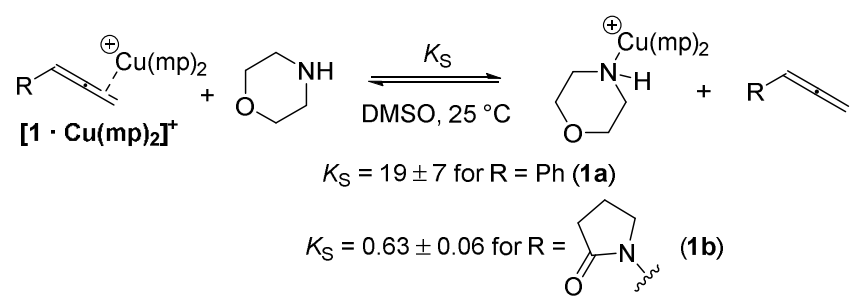

Scheme 2 - Displacement of coordinated allene from cationic $\mathrm{Cu}(\mathrm{I})$ by morpholine. Asymptotic standard errors of the fitting procedure are given as uncertainties (see the Supporting Information, section 1.3 for complete data treatment).

\subsection{The catalytic cycle, and the origin of the selectivity}

The reaction under study has the merit of being regio- and stereoselective, i.e. the unwanted geometric isomer (Z)-2a is not formed in any detectable amount and $\mathbf{2 a} / \mathbf{3 a}$ isomer ratio is $92: 8$ (Scheme 3). ${ }^{3 \mathrm{f}, 20}$

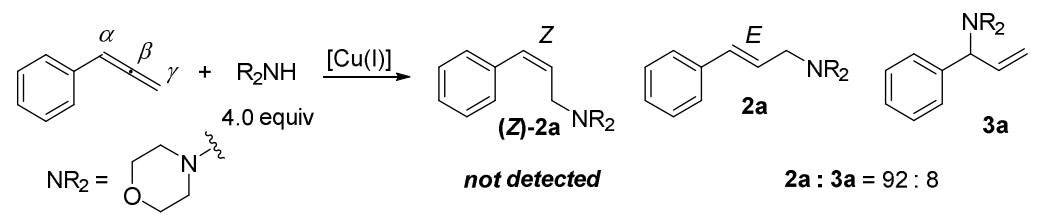

Scheme 3 - Regio- and stereoselectivity of the Cu-catalyzed hydroamination reaction.

In order to prove that the reaction is under kinetic control and that selectivity is not due to equilibration towards the thermodynamically most stable product (2a), $(Z)-\mathbf{2 a}$ and $\mathbf{3 a}$ were synthesized independently and heated under conditions that mimic the catalytic reaction. In both cases, no isomerization to $2 \mathbf{a}$ was detected by ${ }^{1} \mathrm{H}$ NMR analysis of the reaction mixture (Scheme 4). ${ }^{21}$

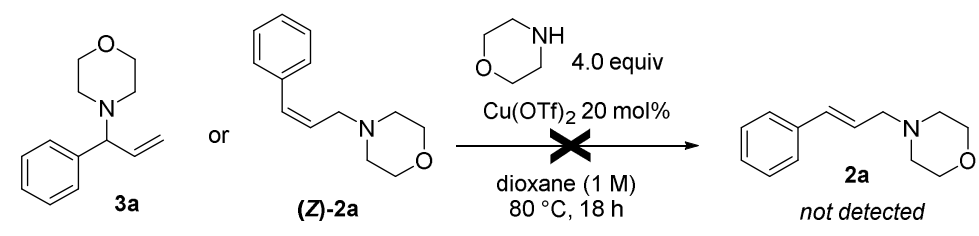

Scheme 4 - Attempted isomerization of (Z)-2a and 3a.

Having in hand reliable experimental information on the nature of the catalyst and its interaction with the substrate, we undertook DFT calculations in order to get insight into the details of the mechanism and to explain the observed selectivity. In the following, we will report Gibbs free energy values computed at $298 \mathrm{~K}$ and $1 \mathrm{~atm}$ on the basis of harmonic frequencies.

The complexation of $\mathrm{Cu}(\mathrm{mp})_{2}{ }^{+}$with phenylallene (1a) is predicted to involve a small variation of Gibbs free energy and can involve either the $\beta, \gamma$ double bond (to give complex I1, $\Delta G=+1.7 \mathrm{kcal} \mathrm{mol}^{-1}$ ) or the $\alpha, \beta$ one (to give complex iso-I1, $\Delta G=-0.5 \mathrm{kcal} \mathrm{mol}^{-1}$ ). ${ }^{22}$ In contradistinction with the findings of Toste and coworkers about a related gold-catalyzed hydroamination reaction involving hydrazide nucleophiles, no stable metal-allyl cation complex could be found. ${ }^{6 a}$ The reaction, thus, must take place by direct attack of the secondary amine nucleophile on the copper-allene complex. An alkenyl-copper intermediate is so formed and it gives the final hydroamination product after protodemetallation. Alkenyl-copper compounds are generally stereochemically stable and undergo stereospecific cleavage of the $\mathrm{C}$ - $\mathrm{Cu}$ bond with retention of configuration in the presence of proton sources. This is the case, for example, of the alkenylcopper reagents formed by stereoselective carbocupration reactions and numerous examples of stereospecific hydrolysis have been described. ${ }^{23}$ The stereoselectivity of the nucleophilic attack, thus, directly determines the final $E$ / $Z$ selectivity. 
For the attack of the incoming morpholine nucleophile on the $\left[\mathrm{Cu}(\mathrm{mp})_{2}\right]^{+}$-phenylallene complex, two idealized stereochemical approaches are conceivable with respect to the plane in which the $\mathrm{C}=\mathrm{CH}_{2}$ moiety lies: 1) from the opposite side, i.e. in an antiperiplanar fashion; and 2) from the same side, i.e. a synperiplanar approach. In either case the $\mathrm{Ph}$ group can rest in the same half-space as the $\mathrm{Cu}(\mathrm{mp})_{2}{ }^{+}$, giving rise to the $Z$ organocopper intermediate, or in the opposite one, generating thus the $E$ alkenylcopper compound. All four possible resulting transition state structures are schematically depicted in Figure 1. For TS1a-b, d the computed geometries and Gibbs free energy of formation ( $\Delta G$, with respect to free $\left[\mathrm{Cu}(\mathrm{mp})_{2}\right]^{+}, \mathrm{mp}$ and 1a) are also reported. The hypothetical TS1c is too sterically congested and any attempt of geometry optimization invariably leads to TS1a. The transition state TS1e for attack at the $\alpha$ position has also be obtained (Figure 1). In the latter case, the $\left[\mathrm{Cu}(\mathrm{mp})_{2}\right]^{+}$moiety is bound to the allene through the $\alpha, \beta$ double bond and attack of the incoming $\mathrm{mp}$ can only happen in an antiperiplanar fashion because of steric hindrance.

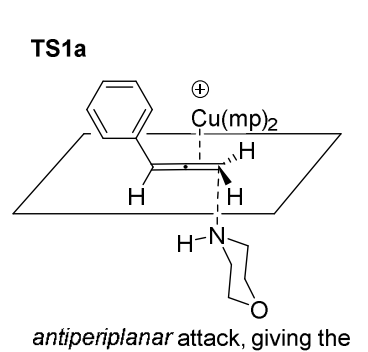

antiperiplanar attack, giving the $Z$ organocopper intermediate

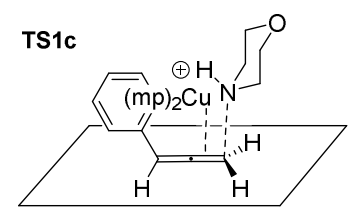

synperiplanar attack, giving the $Z$ organocopper intermediate
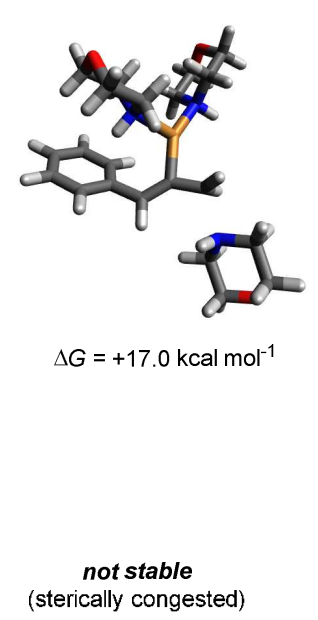

(sterically congested)

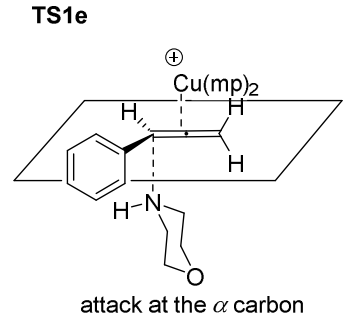

TS1b
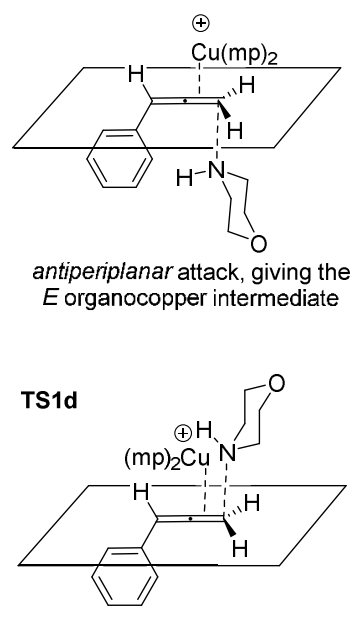

synperiplanar attack, giving the $E$ organocopper intermediate
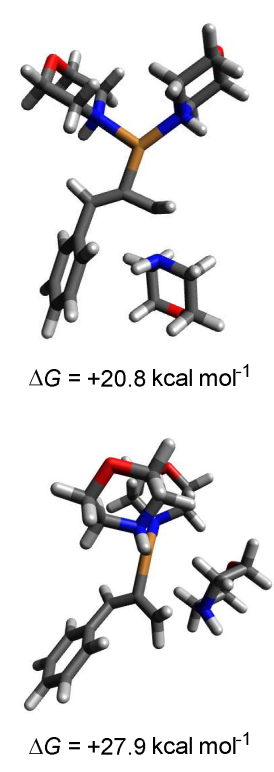

Figure 1 - Modes of nucleophilic attack on the allene / morpholine complex. Reported figures are computed Gibbs free energies at $298 \mathrm{~K}(\Delta G)$ relative to non-interacting $\left[\mathrm{Cu}(\mathrm{mp})_{2}\right]^{+}$, mp and $\mathbf{1 a}$.

Assuming stereospecific protodemetallation with retention of configuration as the product-forming step, TS1a leads to the formation of 2a, TS1b and TS1d provide (Z)-2a and TS1e gives 3a. The computed free energies of activation are in qualitative agreement with the fact that $\mathbf{2 a}$ is the major observed product that prevails over 3a and that $(\boldsymbol{Z})-\mathbf{2 a}$ is not observed at all by NMR analysis, since $G($ TS1a)< $G($ TS1e $)<G($ TS1b $)<G$ (TS1d) with values of 17.0, 18.7, 20.8 and $27.9 \mathrm{kcal} \mathrm{mol}^{-1}$ respectively. Indeed, the free energy difference between TS1a and TS1e corresponds to a Boltzmann ratio $\left(94: 6\right.$ at $\left.80{ }^{\circ} \mathrm{C}\right)$ which is of the same order of magnitude of the observed 2a:1a ratio (92:8).

In order to get more qualitative insight into the reasons of the observed selectivity, distortion-interaction (DI) analysis was performed. ${ }^{24}$ The results are summarized in Table 3. The $\Delta G$ between the transition states 
TS1a-e and the parent complex $\left[(\mathbf{1 a}) \mathrm{Cu}(\mathrm{mp})_{2}\right](\mathbf{I 1})$ has been dissected into the contributions due to solvation $\left(\Delta E_{\text {solvation }}\right)$, thermal correction to Gibbs free energy $\left(\Delta E_{\text {thermal }}\right)$, distortion of morpholine $\left(\Delta E_{\text {dist }}(\mathrm{mp})\right)$ and of the Cu-allene fragment $\left(\Delta E_{\text {dist }}(\mathbf{I 1})\right)$ - the sum of which gives the total distortion contribution $\left(\Delta E_{\text {dist }}=\right.$ $\left.\Delta E_{\text {dist }}(\mathrm{mp})+\Delta E_{\text {dist }}(\mathbf{I} 1)\right)$ - and interaction between the two fragments $\left(\Delta E_{\text {int }}\right)$. All the contributions are quite homogeneous within the series, except for the lower distortion energy found for TS1a and the higher distortion energy computed for TS1d. Moreover, the absolute value of the interaction energy is lower for TS1d than for TS1b and TS1e. In summary, we can conclude that synperiplanar attack is not possible due to stereoelectronic reasons and that the observed selectivity for the linear, $E$ product is largely distortioncontrolled.

Table 1 - Distortion-interaction analysis for TS1a-b and TS1d-e. All reported data are in $\mathrm{kcal} \mathrm{mol}^{-1}$. ${ }^{2}$

\begin{tabular}{|l|c|c|c|c|}
\hline & TS1a & TS1b & TS1d & TS1e \\
\hline$G(\mathbf{T S})-G(\mathbf{I 1})$ & $\mathbf{1 5 . 3}$ & $\mathbf{1 9 . 1}$ & $\mathbf{2 6 . 2}$ & $\mathbf{1 7 . 0}$ \\
\hline & \multicolumn{4}{|l|}{} \\
\hline$\Delta E_{\text {solvation }}$ & 3.4 & 3.5 & 2.9 & 3.5 \\
\hline$\Delta E_{\text {thermal }}$ & 11.8 & 12.1 & 14.3 & 13.9 \\
\hline \multicolumn{5}{|l|}{} \\
\hline$\Delta E_{\text {dist }}(\mathrm{mp})$ & 0.2 & 0.3 & 0.6 & 0.5 \\
\hline$\Delta E_{\text {dist }}(\mathbf{I 1})$ & 12.4 & 20.7 & 24.6 & 17.7 \\
\hline$\Delta E_{\text {dist }}$ (total) & $\mathbf{1 2 . 6}$ & $\mathbf{2 1 . 0}$ & $\mathbf{2 5 . 2}$ & $\mathbf{1 8 . 2}$ \\
\hline$\Delta E_{\text {int }}$ & $\mathbf{- 1 2 . 5}$ & $-\mathbf{1 7 . 5}$ & $-\mathbf{1 6 . 2}$ & $-\mathbf{1 8 . 6}$ \\
\hline
\end{tabular}

${ }^{\mathrm{a}}$ The DI analysis has been performed according to the following formulae: $G(\mathbf{T S})-G(\mathbf{I 1})=\Delta E_{\text {solvation }}+\Delta E_{\text {thermal }}+\Delta E_{\text {dist }}(\mathrm{mp})+$ $\Delta E_{\text {dist }}(\mathbf{I} \mathbf{1})+\Delta E_{\text {int }} ; \Delta E_{\text {dist }}($ total $)=\Delta E_{\text {dist }}(\mathrm{mp})+\Delta E_{\text {dist }}(\mathbf{I} \mathbf{1})$.

The complete catalytic cycle for the pathway going through the TS1a was analyzed at the same level of theory and the computed energy profile is reported in Figure 2. Complexation of phenylallene (1a) with $\left[\mathrm{Cu}(\mathrm{mp})_{2}\right]^{+}$, giving the intermediate complex $\mathbf{I 1}$, is slightly endergonic $\left(\Delta G=+1.7 \mathrm{kcal} \mathrm{mol}^{-1}\right)$, as the association with an extra molecule of morpholine in intermediate $\mathbf{I} 2\left(\Delta G=+3.2 \mathrm{kcal} \mathrm{mol}^{-1}\right)$. Addition of morpholine on the Cu-activated allene takes place as described previously via TS1a $\left(\Delta G^{\sharp}=+12.1 \mathrm{kcal} \mathrm{mol}^{-}\right.$ $\left.{ }^{1}\right)$ in an antiperiplanar fashion giving the $Z$ alkenylcopper intermediate $\mathbf{I 3}\left(\Delta G=+6.7 \mathrm{kcal} \mathrm{mol}^{-1}\right)$ featuring a protonated nitrogen atom. Proton transfer to a morpholine molecule $\left(\Delta G=+5.9 \mathrm{kcal} \mathrm{mol}^{-1}\right)$ allows the latter to engage in almost barrierless stereo-conservative protodemetallation via TS2. This step is exergonic $(\Delta G=$ $-29.8 \mathrm{kcal} \mathrm{mol}^{-1}$ ) and delivers the $E$ product 2a in the conformation I5. This step makes the whole transformation exergonic and it is the driving force of the process. Isomerization to the more stable conformer I6 $\left(\Delta G=-1.8 \mathrm{kcal} \mathrm{mol}^{-1}\right)$ finally takes place. 
Simple inspection of the structure of TS1a suggests that introduction of a substituent at the allene $\alpha$ position should severely interfere with the reactivity, because of unfavorable steric hindrance with incoming nucleophile, in a way akin to allylic 1,3-strain. On the other hand, introduction of a substituent on the $\gamma$ carbon should not affect reactivity much. To test this hypothesis, the reactivity of allenes $\mathbf{1 d}$ and $\mathbf{1 e}$ was examined. In accordance with the expected trend, the $\alpha, \alpha$-disubstituted allene 1d gave an isomeric mixture of hydroamination products in $22 \%$ overall yield only under forcing conditions (reaction temperature: $100{ }^{\circ} \mathrm{C}$ ), while the $\alpha, \gamma$-disubstituted allene 1e gave the expected product (2e) in $52 \%$ yield using the standard ${ }^{3 f}$ protocol (Figure 3). ${ }^{25,26}$

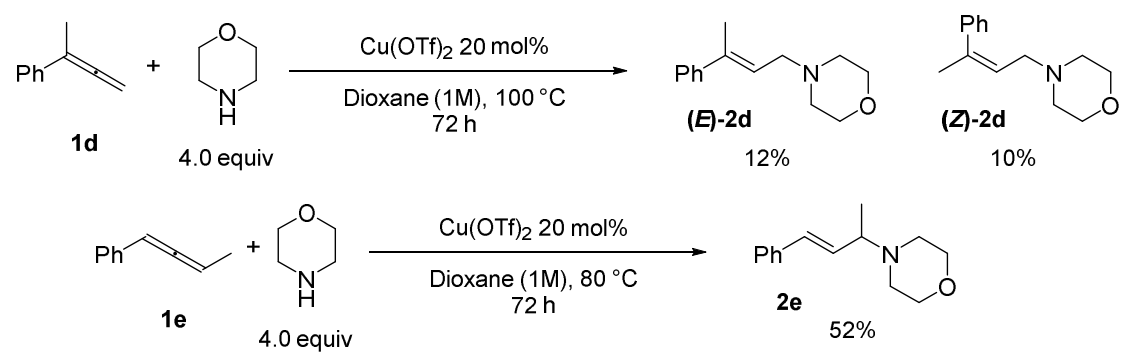

Figure 3 - Hydroamination of disubstitued allenes 1c and 1d. Reported yields were determined by ${ }^{1} \mathrm{H}$ NMR spectroscopy of the crude reaction mixture. ${ }^{26}$

We examined the geometry of the relevant transition state TS1a and compared them to Cu-allene parent complex I1. A significant structural reorganization of the coordinated allene takes place before the formation of the new C-N bond. This view is reinforced by the distortion-interaction analysis shown previously and inspection of the geometric parameters of TS1a (Figure 2) shows that the $\mathrm{C}_{\gamma}-\mathrm{N}$ distance is long $(2.14 \AA$ ) and $\mathrm{C}_{\beta}$ is essentially already a sp ${ }^{2}$ centre $\left(<\mathrm{C}_{\alpha} \mathrm{C}_{\beta} \mathrm{C}_{\gamma}=138.8^{\circ},<\mathrm{CuC}_{\beta} \mathrm{C}_{\gamma} \mathrm{N}=174.5^{\circ},<\mathrm{CuC}_{\beta} \mathrm{C}_{\alpha} \mathrm{H}=170.0^{\circ}\right)$. This way, positive charge is built at the $\gamma$ allenic carbon passing from the I1 to TS1a, as natural population analysis $^{27}$ evidences (Figure 4). 


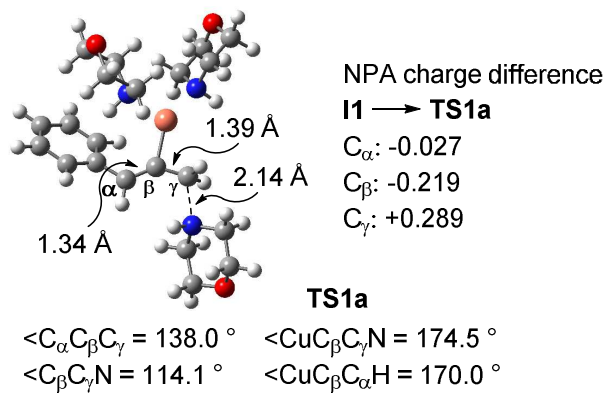

Figure 4 - Selected geometric and parameters for TS1a. NPA charge difference between TS1a and I1 is also shown.

\subsection{From mechanistic insights to methodology development}

In order to extend the applicability of the reaction under study in milder conditions, we reasoned that substitution at the $\alpha$-carbon with a heteroatom having lone pairs could help to stabilize the transition state by mesomeric effect, effectively delocalizing the positive charge developed at $\mathrm{C}_{\gamma}$. With this aim in mind, nitrogen substitution was the most obvious choice. Since $N$-allenylamines are unstable compounds and very prone to polymerization, ${ }^{28}$ we devoted our attention to allenamides, which are often an optimum compromise between reactivity and stability. ${ }^{29}$

We tested the reaction of $N$-allenyl-2-pyrrolidinone (1b) with morpholine under the previously reported conditions ${ }^{3 \mathrm{f}}$ and we found, in agreement with our expectations, that the transformation can indeed proceed at room temperature for this substrate (after pre-reduction of $\mathrm{Cu}(\mathrm{OTf})_{2}$ with morpholine for $10 \mathrm{~min}$ at $80{ }^{\circ} \mathrm{C}$, Table 4, entry 1). Reducing the excess of morpholine (entry 3 ) had a detrimental effect on the yields with this catalyst. A screening performed using the $\mathrm{Cu}(\mathrm{I})$ catalyst $\mathrm{Cu}(\mathrm{NCMe})_{4}(\mathrm{OTf})$ (entries 4-9) revealed that the reaction is most efficient in solvents of medium to low polarity (e.g. THF and benzene). ${ }^{30}$ Finally, we found that air-stable and commercially available $\mathrm{Cu}(\mathrm{NCMe})_{4} \mathrm{PF}_{6}$ promotes the reaction in almost quantitative yield at room temperature with a comparatively low catalyst loading of $5 \mathrm{~mol} \%$ in the presence of only 1.2 equiv of secondary amine, provided that THF is used as a solvent (entry 13). These very mild conditions complement a known method for the hydroamination of allenamides with primary anilines under gold catalysis. $^{31}$

Table 4 - Optimization of the reaction conditions for the $\mathrm{Cu}$-catalyzed hydroamination of allenamides.

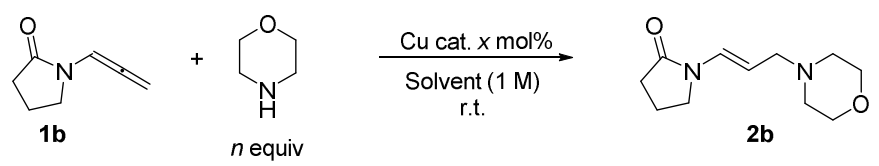

\begin{tabular}{|c|c|c|c|c|c|}
\hline Entry & Catalyst (mol\%) & Solvent & mp (equiv) & Time (h) & Yield $(\%)^{\mathrm{a}}$ \\
\hline 1 & $\mathrm{Cu}(\mathrm{OTf})_{2}(20)$ & dioxane & 4.0 & 1.5 & $83^{b}$ \\
\hline 2 & $\mathrm{Cu}(\mathrm{OTf})_{2}(20)$ & dioxane & 2.0 & 1.5 & $82^{b}$ \\
\hline 3 & $\mathrm{Cu}(\mathrm{OTf})_{2}(20)$ & dioxane & 1.2 & 4 & $50^{b}$ \\
\hline 4 & $\mathrm{Cu}(\mathrm{NCMe})_{4}(\mathrm{OTf})(20)$ & dioxane & 1.2 & 4 & 54 \\
\hline 5 & $\mathrm{Cu}(\mathrm{NCMe})_{4}(\mathrm{OTf})(20)$ & $\mathrm{CHCl}_{3}$ & 1.2 & 2 & $49^{c}$ \\
\hline 6 & $\mathrm{Cu}(\mathrm{NCMe})_{4}(\mathrm{OTf})(20)$ & benzene & 1.2 & 2 & 58 \\
\hline 7 & $\mathrm{Cu}(\mathrm{NCMe})_{4}(\mathrm{OTf})(20)$ & $\mathrm{MeCN}$ & 1.2 & 5 & 45 \\
\hline 8 & $\mathrm{Cu}(\mathrm{NCMe})_{4}(\mathrm{OTf})(20)$ & $\mathrm{MeOH}$ & 1.2 & 5 & 25 \\
\hline 9 & $\mathrm{Cu}(\mathrm{NCMe})_{4}(\mathrm{OTf})(20)$ & THF & 1.2 & 1 & 53 \\
\hline 10 & $\mathrm{Cu}(\mathrm{NCMe})_{4} \mathrm{PF}_{6}(20)$ & dioxane & 1.2 & 0.25 & 60 \\
\hline 11 & $\mathrm{Cu}(\mathrm{NCMe})_{4} \mathrm{PF}_{6}(10)$ & dioxane & 1.2 & 1.5 & 60 \\
\hline 12 & $\mathrm{Cu}(\mathrm{NCMe})_{4} \mathrm{PF}_{6}(5)$ & dioxane & 1.2 & 4 & 66 \\
\hline 13 & $\mathrm{Cu}(\mathrm{NCMe})_{4} \mathrm{PF}_{6}(5)$ & THF & 1.2 & 5 & $96(90)^{d}$ \\
\hline
\end{tabular}




\begin{tabular}{|c|c|c|c|c|c|}
\hline 14 & $\mathrm{Cu}\left(\mathrm{NCMe}_{4} \mathrm{PF}_{6}(2.5)\right.$ & THF & 1.2 & 18 & 25 \\
\hline 15 & None & THF & 1.2 & 18 & 0 \\
\hline
\end{tabular}

${ }^{a}$ Determined by ${ }^{1} \mathrm{H}-\mathrm{NMR}$ with 1,3,5-trimethoxybenzene as an internal standard. ${ }^{b}$ Reaction performed at room temperature after preactivation of the catalyst for $10 \mathrm{~min}$ at $80{ }^{\circ} \mathrm{C}$ in the absence of allene. ${ }^{c} 20 \%$ of the branched product formed, that decomposed slowly in the reaction mixture. ${ }^{\mathrm{d}}$ Isolated yield.

With this efficient catalyst system in hand, we explored the scope of the reaction by varying the allene partner (Scheme 5). A variety of allenamides, featuring aromatic or aliphatic substituents are viable substrates for this reaction. If $N$-aryl- $N$-allenyl amides are employed, both electron-releasing and electronwithdrawing groups are tolerated (compounds $\mathbf{2 f - i}$ ). In addition to allenamides, $N$-allenylcarbamates react smoothly under the optimized conditions (compounds 2n-o). Importantly, Evans oxazolidinone derivative 20 was obtained in good yield. Given that as for all other examples the $E$ double bond isomer was obtained with complete selectivity, $\mathbf{2 0}$ could be an interesting substrate for diastereoselective reactions involving the enamide moiety. ${ }^{32}$
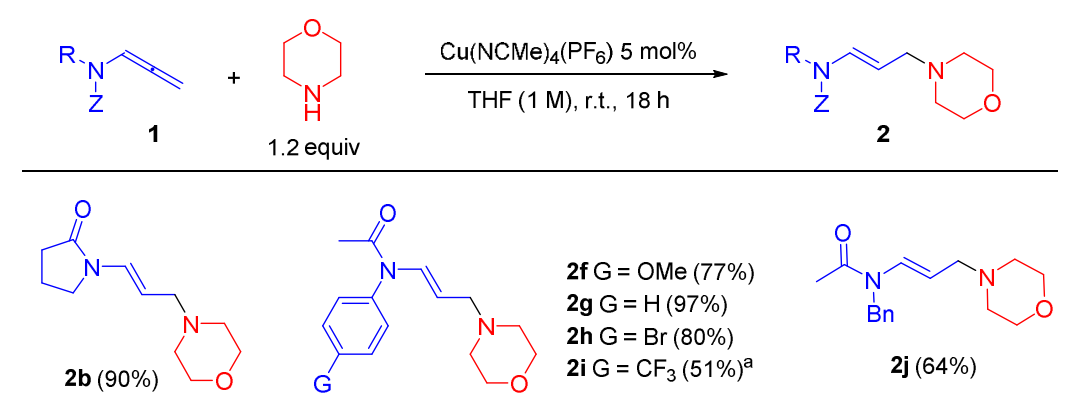

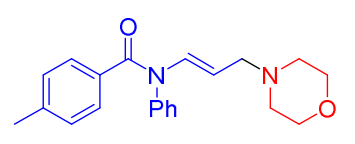

$2 \mathbf{k}(78 \%)$

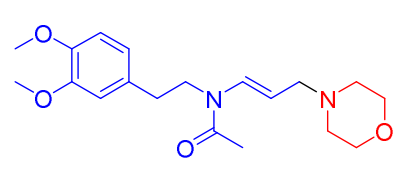

2l $(63 \%)^{\mathrm{a}}$
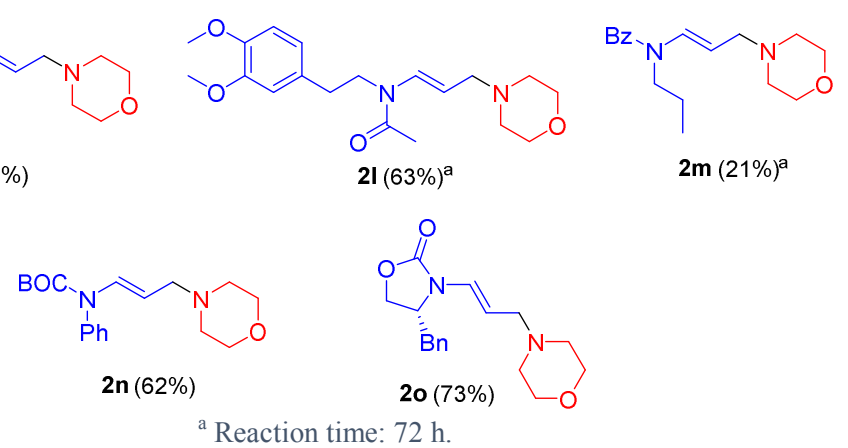

Scheme 5 - Cu-catalyzed hydroamination of various allenamides and $N$-allenylcarbamates with morpholine.

The scope with respect to the amine was also investigated (Scheme 6). A variety of secondary amines are suitable substrates, including sterically open-chain aliphatic amines and sterically hindered ones (2s, 2aa) that are not very reactive under the conditions we described previously for the hydroamination of simple allenes. ${ }^{3 f}$ These mild reaction conditions also tolerate several functional groups, such as bromo (2h) and iodo (2u) substituents, unprotected $\mathrm{OH}$ groups (2t) and boronic esters (2v), which can be employed in subsequent transformations. Importantly, a pharmaceutically relevant pyridine ring does not hamper reactivity (2v). 

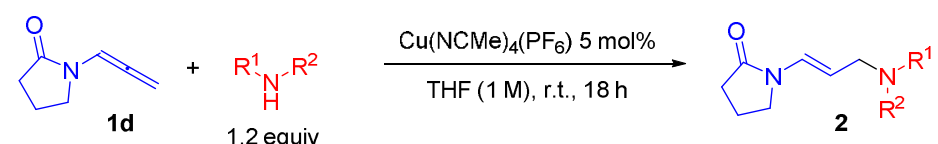

10 1.2 equiv $2 \mathrm{R}$

The enamide moiety is a valuable platform for further transformations. For instance, the 1-aminoethyl$(1,2,3,4)$-tetrahydroisoquinoline and 1 -aminoethyl-(1,2,3,4)-tetrahydro- $9 H$ - $\beta$-carboline skeletons should be accessible by Pictet-Spengler type cyclization of suitable allenamide hydroamination products. These structural motifs occur in a variety of biologically active molecules, such as the marine alkaloids Tarennine ${ }^{33}$ and Keramamine $\mathrm{C}^{34}$ and some experimental APIs ${ }^{35}$ (Figure 5). As a proof of concept, we prepared $O$ - and $\mathrm{N}$-protected P-3374 (6), a drug candidate that has been investigated as a treatment for vascular ailments. ${ }^{35 a}$ The complete synthetic sequence starting from commercially available homoveratrylamine 4 is reported in Scheme 7. Allenamide $1 \mathbf{k}$ was prepared according to a standard sequence ${ }^{29,36}$ by $N$-propargylation of $N$ acetyl-homoveratrylamine and $t$-BuOK-catalyzed isomerization. Hydroamination with morpholine using our optimized conditions and subsequent TFA-mediated electrophilic cyclization afforded the required tetrahydroisoquinoline 6 in overall $31 \%$ yield over five steps.

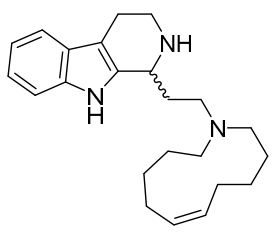

Keramamine $\mathrm{C}$

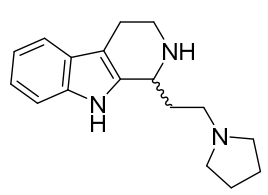

Tarennine

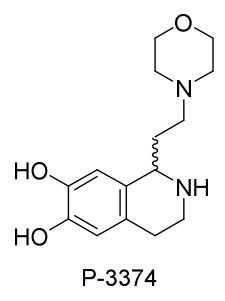

Vasodilato

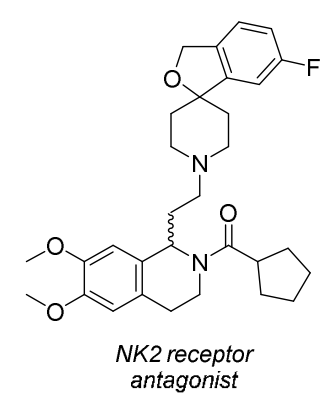

Figure 5 - Natural products and experimental APIs containing the 1-aminoethyl-(1,2,3,4)-tetrahydroisoquinoline and 1-aminoethyl$(1,2,3,4)$-tetrahydro- $9 H$ - $\beta$-carboline skeleton. ${ }^{33-35}$ 


\subsection{Mechanistic insight into the hydroamination of allenamides}

Having established an efficient protocol for the hydroamination of allenamides under very mild conditions, we went back to mechanistic studies to gain insight into the details of this reaction and make comparisons with the reaction of carbon-only allenes we studied previously.

We have already shown (Table 1, entry 2) that $N$-allenyl-2-pyrrolidinone (1b), as a representative allenamide, has greater affinity for cationic copper than phenylallene (1a). The transition states corresponding to the antiperiplanar attack of the amine nucleophile that we have established previously for the hydroamination of phenylallene have been located at the DFT level of theory (Figure 6). The carbonyl oxygen of the enamide moiety plays an important role in the energetics of these transition states. Transition state TS3b in which the amide oxygen coordinates copper (O-Cu distance: $2.22 \AA$ ) while the nucleophilic attack of morpholine takes place is $3.9 \mathrm{kcal} \mathrm{mol}^{-1}$ more stable than its conformer TS3a, for which this interaction is not possible. This oxygen atom can also engage in a hydrogen-bond with the incoming amine (O-H distance: $1.95 \AA$ ), provided that the attack of morpholine is such that the product is the $E$ vinylcopper intermediate (TS3c). This transition state is predicted to be almost as stable as TS3a, but significantly less than TS3b and it would lead to the $Z$ enamide, which is not observed experimentally. TS3d, which in the end also gives the $Z$ enamide after synperiplanar attack is decidedly more endergonic than all the others are.

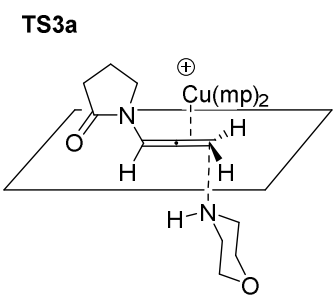

TS3C

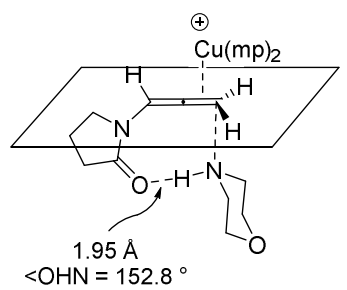

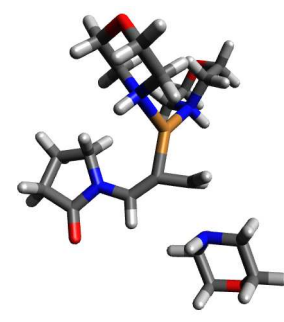

$\Delta G=+18.2 \mathrm{kcal} \mathrm{mol}^{-1}$

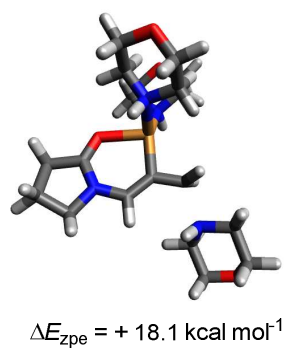

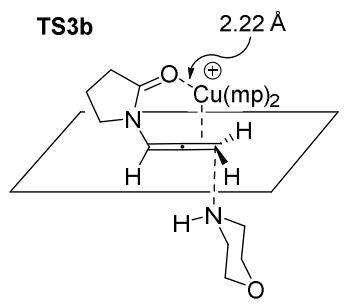

TS3d

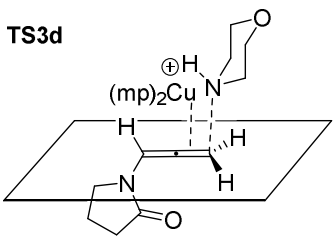

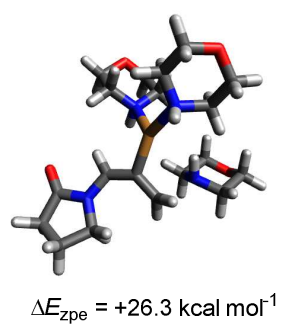

$\Delta E_{\mathrm{zpe}}=+26.3 \mathrm{kcal} \mathrm{mol}^{-1}$

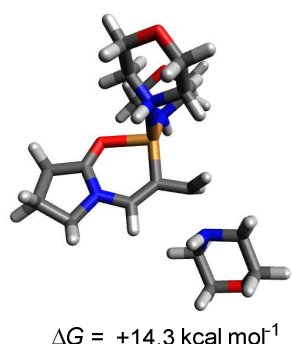

$\Delta G=+14.3 \mathrm{kcal} \mathrm{mol}^{-1}$

Figure 6 - Transition states for the attack of $\mathrm{mp}$ on $\mathrm{Cu}$-coordinated allenamide 1b. Reported figures are computed Gibbs free energies in $\mathrm{kcal} \mathrm{mol}^{-1}$ at $298 \mathrm{~K}$ with respect to non-interacting $\left[\mathrm{Cu}(\mathrm{mp})_{2}\right]^{+}, \mathrm{mp}$ and $\mathbf{1 b}$. 
The overwhelming stability of TS3b with respect to all transition states accounts for the complete $E$ stereoselectivity of the transformation. This transition state, indeed, leads to a $Z$ alkenylcopper intermediate, which after stereospecific hydrolysis gives the $E$ enamide. The whole reaction pathway passing through TS3b has been studied computationally (Figure 7, top). The picture is similar to that reported for the hydroamination of phenyllallene (1a, Figure 2), but the energetics are different because of the different electronic properties of the allenamide and the ability to coordinate $\mathrm{Cu}(\mathrm{I})$ through the amide oxygen. Complexation of the $\left[\mathrm{Cu}(\mathrm{mp})_{2}\right]^{+}$moiety with $\mathbf{1 b}$ to give is exergonic $\left(\Delta G=-6.6 \mathrm{kcal} \mathrm{mol}^{-1}\right)$ and gives intermediate I7, which can associate with a further molecule of morpholine, yielding I8 $\left(\Delta G=+1.1 \mathrm{kcal} \mathrm{mol}^{-}\right.$ $\left.{ }^{1}\right)$. Addition of $\mathrm{mp}$ to the double bond takes place via $\mathbf{T S 3 b}\left(\Delta G^{\ddagger}=+19.8 \mathrm{kcal} \mathrm{mol}^{-1}\right)$ and gives the $N$ protonated alkenylcopper intermediate $\mathbf{I 9}\left(\Delta G=+16.5 \mathrm{kcal} \mathrm{mol}^{-1}\right)$. Deprotonation of $\mathbf{I 9}$ by an external mp molecule leading to $\mathbf{I 1 0}$ is favorable $\left(\Delta G=-3.0 \mathrm{kcal} \mathrm{mol}^{-1}\right)$. The morpholinium ion carries out the exergonic $\left(\Delta G=-27.3 \mathrm{kcal} \mathrm{mol}^{-1}\right)$, essentially barrierless $\left(\Delta G^{*}=+0.6 \mathrm{kcal} \mathrm{mol}^{-1}\right)$, stereoconservative protodecupration via TS4, which results in I11. Dissociation from copper and conversion of the intermediate $\mathbf{I 1 2}$ so formed to a more stable rotamer $\mathbf{I 1 3}$ deliver the final product $\mathbf{2 b}$ and regenerate the catalyst.

The main geometrical features of TS3b are very similar to that of TS1a (see Figure 7, bottom), the main differences being that the forming $\mathrm{C}-\mathrm{N}$ bond is shorter $(2.00 \AA$, i.e. the transition state is more product-like) and that less positive charge is accumulated on the $\gamma$ allenic carbon (NBO charge difference for I7 $\rightarrow$ TS3b is +0.267 , i.e. about $10 \%$ less than for I1 $\rightarrow$ TS1a). It is worth noting that the forming C-N bond lies approximately in the same plane as the $\mathrm{C}_{\alpha}=\mathrm{C}_{\beta}$ moiety, so that overlap between the $\pi$ system encompassing $\mathrm{C}_{\alpha}$ and $\mathrm{C}_{\beta}$ and the $\sigma$ orbital associated with the forming bond is poor, compatibly with relatively modest charge stabilization observed.

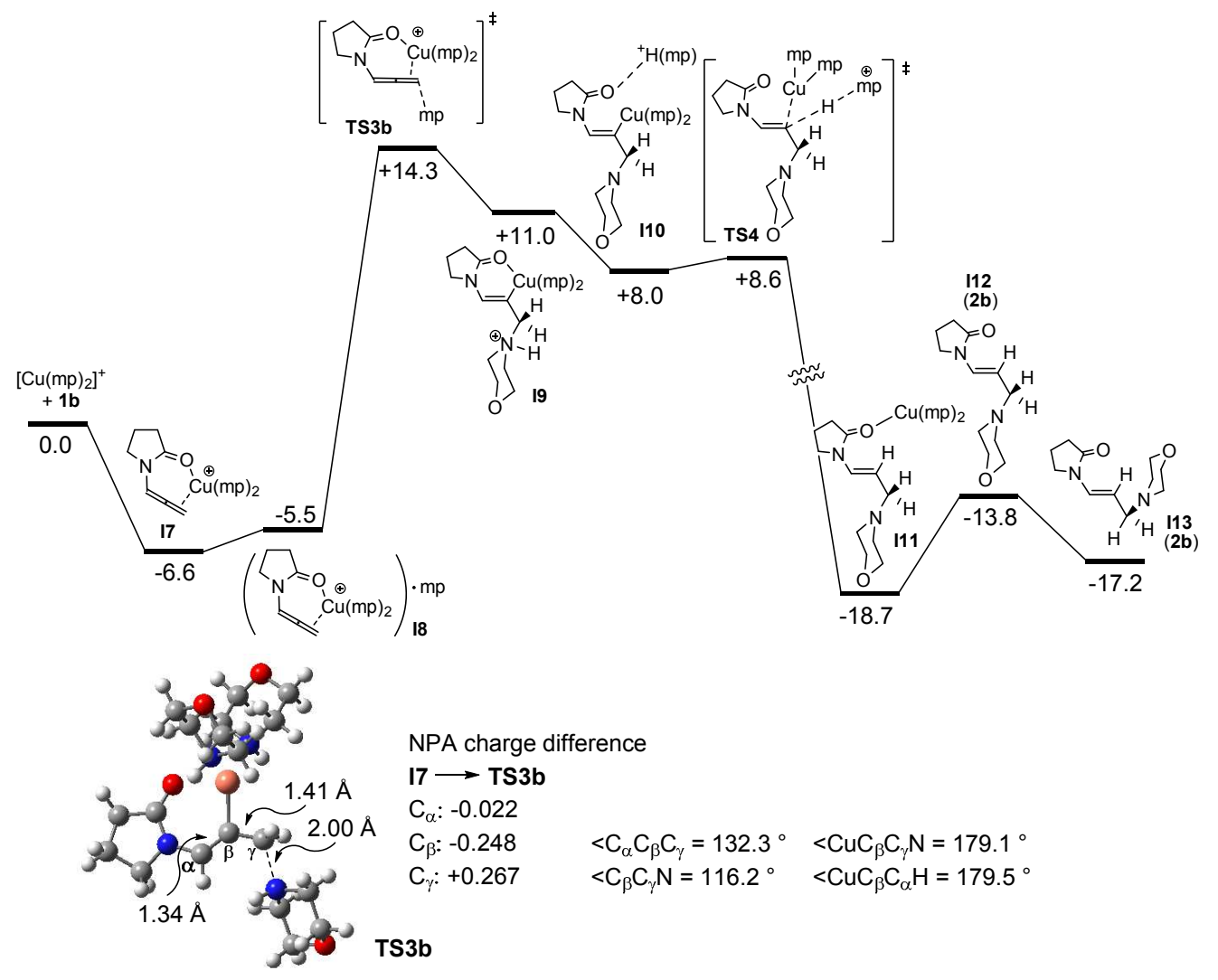

Figure 7 - Computed reaction pathway for the Cu-catalyzed hydroamination of $N$-allenyl-2-pyrrolidinone (1b) with morpholine. Reported numbers are computed relative Gibbs free energies in $\mathrm{kcal} \mathrm{mol}^{-1}$ at $298 \mathrm{~K}$. Selected geometric parameters for TS3b and NPA charge difference between TS3b and $\mathbf{I} 7$ are also reported. 
In order to confirm the theoretical predictions, the kinetics of the reaction were studied experimentally (Figure 8). ${ }^{37}$ The disappearance of the ${ }^{1} \mathrm{H}-\mathrm{NMR}$ resonance of $\mathrm{H}_{\alpha}$ of the starting material $\mathbf{1 b}$ and the appearance of the signal for $\mathrm{H}_{\beta}$ of the product $\mathbf{2 b}$ could be easily monitored. The kinetics fitted first-order equations when mp was used in excess and apparent first-order rate constants $k_{\text {app }}$ could then be obtained (Figure 8A). The reaction is first order with respect to the allenamide substrate $\mathbf{1 b}$ and first order with respect to the catalyst (Figure $8 \mathrm{C}$ ), so at a fixed excess of $\mathrm{mp}$ :

$$
\frac{\mathrm{d}[\mathbf{2 b}]}{\mathrm{d} t}=k_{\mathrm{app}}[\mathbf{1 b}] \quad k_{\mathrm{app}}=k^{\prime}\left[\mathrm{Cu}^{+}\right]
$$

The formation of dimeric or higher-order polymetallic species is thus not to be expected. The dependence of pseudo-first order rate constants $k_{\text {app }}$ on the concentration of mp is more complex (Figure 8B). At low concentrations $(<0.75 \mathrm{M}), k_{\text {app }}$ increases with the concentration of $\mathrm{mp}$, until it reaches a maximum around $[\mathrm{mp}]=0.75 \mathrm{M}$. At higher concentrations, $k_{\text {app }}$ decreases slightly with [mp]. This bell-shaped curve can be interpreted qualitatively by considering that the reaction should be first-order with respect to mp, assuming an outer-sphere attack of the nucleophile in agreement with DFT calculations. However, mp displaces the allene from the catalyst, thus inhibiting the reaction. The fact that the curve in Figure 8B is not a simple hyperbolic rise to a maximum, as expected if morpholine behaved as a typical competitive inhibitor, suggests that $\mathrm{mp}$ intervenes also in a different way in the equilibria involving the catalyst. For instance, the decrease of the observed rate at high $[\mathrm{mp}]$ is consistent with the formation of higher-coordinated copper species. $^{38}$

A

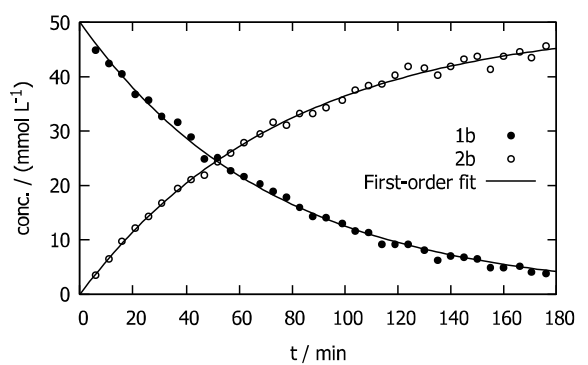

B

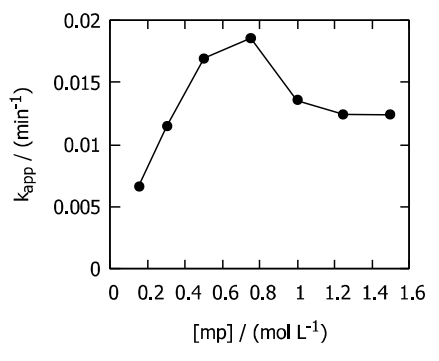

$\mathrm{C}$

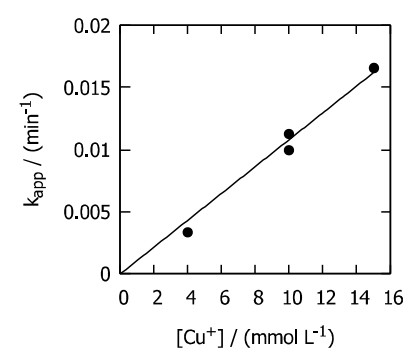

Figure 8 - Kinetics of the reaction between $N$-allenyl-2-pyrrolidinone $\left(\mathbf{1 b}, 50 \mathrm{mM}\right.$ in dioxane) at $25^{\circ} \mathrm{C}$ catalyzed by $\mathrm{Cu}(\mathrm{NCMe})_{4} \mathrm{PF}_{6}$, as followed by ${ }^{1} \mathrm{H}-\mathrm{NMR}$ spectroscopy, under different conditions: A) With mp (20 equiv) and 20 mol\% catalyst loading. The concentration of starting material $\mathbf{1 b}$ and product $\mathbf{2 b}$ are reported, together with first-order rate equation fitting. B) With varying amounts of $\mathrm{mp}$ and $20 \mathrm{~mol} \%$ catalyst loading. The dependence of the apparent first-order rate constant on [mp] is shown. C)

With $\mathrm{mp}$ (12.5 equiv) and varying amounts of catalyst. The apparent first-order rate constant is reported as a function of the concentration of the catalyst itself.

With the aim to confirm our initial assumption about the polarity of the transition state for the hydroamination reaction, i.e. that positive charge is built up and stabilized by the allenamide nitrogen atom, we performed a Hammett study on para-substituted $N$-allenylacetanilides 1f-i. When these compounds were reacted with excess mp (10 equiv), pseudo-first order kinetics were observed and the apparent rate constants showed excellent correlation with Hammett's $\sigma_{\mathrm{P}}$ parameters (Figure 9, see the Supporting Information, section 1.5 for detailed data treatment) ${ }^{39}$ In agreement with our hypothesis, electron-rich substrates react faster than electron-poor ones, giving a negative $\rho$ parameter $(\rho=-0.336$, Figure 9$)$. The observed relative reactivity order is also in qualitative agreement with DFT calculations (see the Supporting Information, section 1.5). 


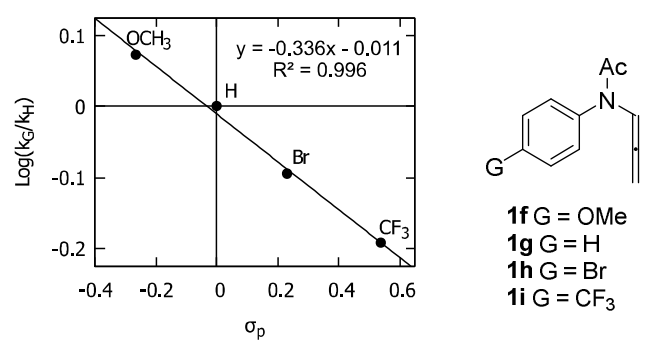

Figure 9 - Hammett plot for the hydroamination of para-substituted $N$-allenylacetanilides 1f-i (conditions: mp 10 equiv, $\mathrm{Cu}(\mathrm{NCMe})_{4} \mathrm{PF}_{6} 20 \mathrm{~mol} \%$, THF, $20^{\circ} \mathrm{C}$, initial concentration of $\left.1: 0.5 \mathrm{M}\right)$.

To differentiate the effects of the coordination of the allenamide oxygen from the electronic effects of the heteroatom substitution on the allenyl system, phenoxyallene (1ad) was tested as a substrate devoid of any additional metal-coordinating moiety. This compound, indeed, proved to be even more reactive than allenamides. Its reaction with morpholine under standard conditions was complete in less than one hour at room temperature (Scheme 8). Interestingly, the reaction was not stereoselective, and the $E$ and $Z$ vinyl ether products ( $\boldsymbol{E}-\mathbf{2 a d}$ and $\boldsymbol{Z}$-2ad) formed in 1:1 ratio (Scheme 8).
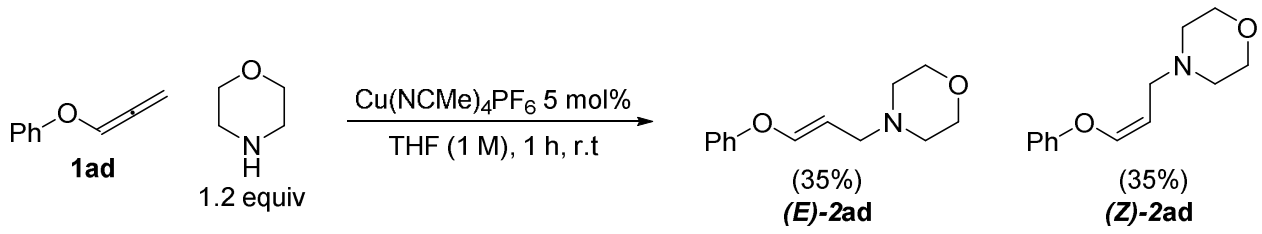

Scheme 8 - Hydroamination of phenoxyallene (1ad). Yields were determined by ${ }^{1} \mathrm{H}$ NMR analysis of the crude reaction mixture.

Inspection of the computed transition states TS5a-b for the formation of the two possible stereoisomeric vinyl-copper intermediates, that are practically isoenergetic $\left(\Delta \Delta G=0.6 \mathrm{kcal} \mathrm{mol}^{-1}\right)$, reveals the existence of two key-hydrogen bonds between $\mathrm{mp}$ and the allene oxygen (Figure 10). NBO charge analysis shows that the accumulation of positive charge passing from the intermediate $\pi$ complex of 1ad with the catalyst to TS5a-b is (on average) $22 \%$ less than that for for I1 $\rightarrow$ TS1a (see the Supporting Information, section 1.5 for the details).
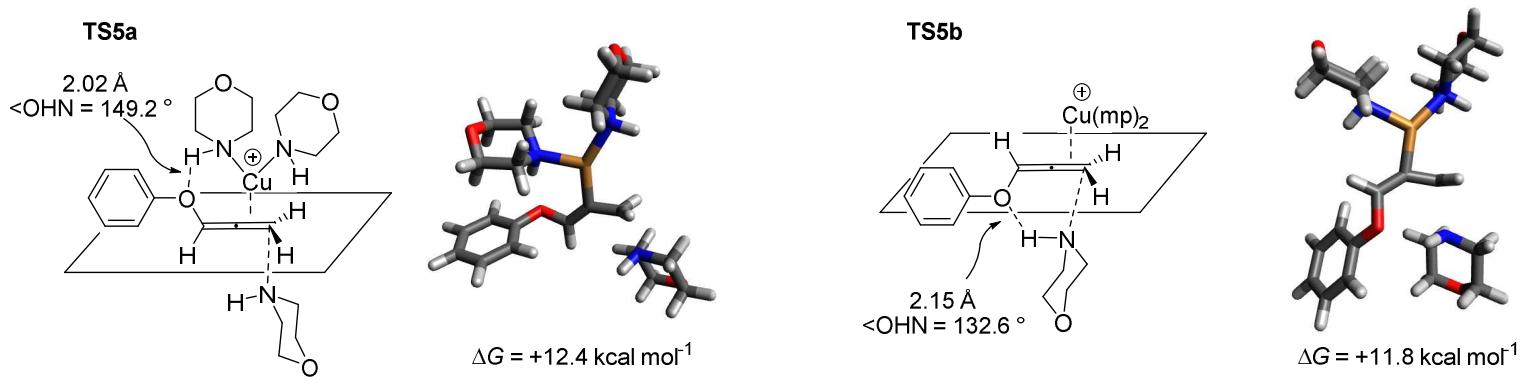

Figure 10 - Transition states for the attack of mp on $\mathrm{Cu}$-coordinated allenamide $\mathbf{1 a d}$

As it is apparent from this latter example, a subtle interplay of sterics, electronic effects and secondary interactions - either with the catalysts or with the incoming nucleophile - tunes the reactivity and governs the selectivity of the Cu-catalyzed hydroamination of heteroatom-substituted allenes.

\section{Conclusions}

We have performed a mechanistic study on the Cu-catalyzed hydroamination of terminal allenes to give $E$ tertiary allylamines. ${ }^{3 \mathrm{f}}$ After adducing evidence that the actual catalytic species is cationic $\mathrm{Cu}(\mathrm{I})$ generated in situ by reduction of a $\mathrm{Cu}(\mathrm{II})$ precursor, we used DFT modeling to explain the regio- and stereoselectivity of the reaction. 
Insight into the mechanism of reaction spurred the extension of the reaction to allenamides, which are reactive under exceptionally mild conditions and with low catalyst loading, challenging the supremacy of Au-based protocols for this transformation. The generality and functional group tolerance of this transformation has been explored and its potential for the synthesis of a biologically active molecule has been demonstrated.

Additional mechanistic analysis revealed the important role of the amide oxygen atom as a coordination site for the catalyst and the inhibitory effect of high concentration of the amine substrate.

Further studies are underway to extend reaction to other classes of substrates and to apply it in asymmetric synthesis. More generally, we also plan to investigate at what conditions and to what extent copper catalysis can replace gold and other precious metals in the activation of unsaturated compounds.

\section{Computational details}

All DFT calculations were performed with the Gaussian09 program (Rev. E.01). ${ }^{40}$ The structures of all minima and transition states were fully optimized using the B3LYP functional ${ }^{41}$ with Grimme's D3 empirical correction for dispersion ${ }^{42}$ comprising the modified Becke-Johnson dumping function ${ }^{43}$ (B3LYP-D3BJ). The following basis set was used for geometry optimizations: $6-31+\mathrm{G}^{*}$ for $\mathrm{N}, \mathrm{O}, \mathrm{F}$ and allene $\mathrm{C} ; 6-31 \mathrm{G}^{*}$ for $\mathrm{H}$ and $\mathrm{C}$ (excluding allene carbons); LANL2TZ(f) with the associated effective core potential (ECP) for $\mathrm{Cu},{ }^{44}$ ${ }^{45}$ and LANL2DZ(d,p) with the associated effective core potential for $\mathrm{Br}^{44,46}$ Single-point calculations were performed to obtain more accurate electronic energies with a larger basis set: $6-311+G(2 d, 2 p)$ for $C, H, N$, $\mathrm{O}$, F; LANL08+(f) with the associated ECP for $\mathrm{Cu} ;{ }^{44,45}$ LANL08(d) with the associated ECP for Br. ${ }^{44,45 b, 46}$ To simulate experimental conditions, bulk solvent effects were accounted for by using an implicit solvation model (IEF-PCM) as implemented in Gaussian. ${ }^{47}$ The default spheres radii, static and optical dielectric constants for 1,4-dioxane or THF were used. All stationary points were characterized as minima or firstorder transition states by analytical frequency calculations. IRC calculations were used to confirm that transition states linked the proper minima. Computed harmonic frequencies were used to calculate the thermal contribution to Gibbs free energy with the usual approximations. Temperature and pressure were fixed at $298 \mathrm{~K}$ and $1 \mathrm{~atm}$, respectively.

\section{Experimental section}

\section{General procedure for the hydroamination of allenamides}

An NMR tube (5 mm diameter) or a Schlenk flask of appropriate size was charged with $\mathrm{Cu}(\mathrm{NCMe})_{4} \mathrm{PF}_{6}$ ( 0.05 equiv) and closed with a rubber septum. After evacuation and back-filling with Ar repeatedly for three times, dry THF ( $1 \mathrm{~mL}$ per mmol of substrate), the required secondary amine (1.2 equiv) and the allenamide (1.0 equiv) were sequentially added. The vessel was shaken until a completely homogeneous solution resulted and the mixture was left overnight at room temperature. Complete conversion was checked by no-D ${ }^{1} \mathrm{H} \mathrm{NMR},{ }^{7}$ taking into consideration the disappearance of the characteristic allene resonances.

The tube was opened to the air and the content poured into 10 volumes of EtOAc and partitioned with 3 volumes of saturated $\mathrm{NaCl}$ aqueous solution. The aqueous phase was back-extracted with EtOAc $(3 \times 3$ volumes) and the combined organic phases were exsiccated over $\mathrm{Na}_{2} \mathrm{SO}_{4}$. Volatiles were evaporated under reduced pressure and the residue was purified by flash chromatography on $\mathrm{NaHCO}_{3}$-treated silica gel $^{48}$ to afford the required hydroamination product.

\section{Associated Content}

Supporting Information 
Additional mechanistic data, experimental details, characterization of starting materials and products, computational data, copies of NMR spectra.

\section{Author Information}

Corresponding authors

* Email for L. A. P.: luca.perego@ens.fr

* Email for F. M.: florian.monnier@enscm.fr

* Email for M. T.: marc.taillefer@enscm.fr

* Email for I. C.: ilaria.ciofini@chimie-paristech.fr

*Email for L. G.: laurence.grimaud@ens.fr

\section{Acknowledgements}

We thank CNRS, ENSCP, and ENS, as well as the ANR program CD2I (project CuFeCCBond) for financial support. FM acknowledges the support of IUF.

\section{References}

(1) Selected reviews on the topic: (a) Mueller, T. E.; Beller, M. Chem. Rev. 1998, 98, 675-703. (b) Brunet, J.-J.; Neibecker, D. In Catalytic Heterofunctionalization; Togni, A., Grützmacher, H., Eds.; WILEY-VCH Verlag: Weinheim, 2001; pp 91-142. (c) Pohlki, F.; Doye, S. Chem. Soc. Rev. 2003, 32, 104-114. (d) Alonso, F.; Beletskaya, I. P.; Yus, M. Chem. Rev. 2004, 104, 3079-3160. (e) Beller, M.; Seayad, J.; Tillack, A.; Jiao, H. Angew. Chem. Int. Ed. 2004, 43, 3368-3398. (f) Widenhoefer, R. A.; Han, X. Eur. J. Org. Chem. 2006, 2006, 4555-4563. (g) Severin, R.; Doye, S. Chem. Soc. Rev. 2007, 36, 1407-1420. (h) Müller, T. E.; Hultzsch, K. C.; Yus, M.; Foubelo, F.; Tada, M. Chem. Rev. 2008, 108, 3795-3892. (i) Yadav, J. S.; Antony, A.; Rao, T. S.; Subba Reddy, B. V. J. Organomet. Chem. 2011, 696, 16-36. (j) Corma, A.; Leyva-Pérez, A.; Sabater, M. J. Chem. Rev. 2011, 111, 1657-1712. (k) Patil, N. T.; Kavthe, R. D.; Shinde, V. S. Tetrahedron 2012, 68, 80798146. (1) Zeng, X. Chem. Rev. 2013, 113, 6864-6900. (m) Reznichenko, A. L.; Hultzsch, K. C. In Hydrofunctionalization - Topics in Organometallic Chemistry; Ananikov, V. P., Tanaka, M., Eds.; SpringerVerlag: Berlin, Heidelberg, 2012; Vol. 43, pp 51-114. (n) Nishina, N.; Yamamoto, Y. In Hydrofunctionalization - Topics in Organometallic Chemistry; Ananikov, V. P., Tanaka, M., Eds.; SpringerVerlag: Berlin, Heidelberg, 2013; Vol. 43, pp 115-143. (o) Evano, G.; Gaumont, A.-C.; Alayrac, C.; Wrona, I. E.; Giguere, J. R.; Delacroix, O.; Bayle, A.; Jouvin, K.; Theunissen, C.; Gatignol, J.; Silvanus, A. C. Tetrahedron 2014, 70, 1529-1616. (p) Huang, L.; Arndt, M.; Gooßen, K.; Heydt, H.; Gooßen, L. J. Chem. Rev. 2015, 115, 2596-2697. (q) Bernoud, E.; Lepori, C.; Mellah, M.; Schulz, E.; Hannedouche, J. Catal. Sci. Technol. 2015, 5, 2017-2037. (r) Coman, S. M.; Parvulescu, V. I. Org. Process Res. Dev. 2015, 19, 1327-1355.

(2) (a) Greenhalgh, M. D.; Jones, A. S.; Thomas, S. P. ChemCatChem 2015, 7, 190-222. (b) Huehls, C. B.; Lin, A.; Yang, J. Org. Lett. 2014, 16, 3620-3623. (c) Bernoud, E.; Oulié, P.; Guillot, R.; Mellah, M.; Hannedouche, J. Angew. Chem. Int. Ed. 2014, 53, 4930-4934.

(3) (a) Rucker, R. P.; Whittaker, A. M.; Dang, H.; Lalic, G. J. Am. Chem. Soc. 2012, 134, 6571-6574. (b) Zhu, S.; Niljianskul, N.; Buchwald, S. L. J. Am. Chem. Soc. 2013, 135, 15746-15749. (c) Miki, Y.; Hirano, K.; Satoh, T.; Miura, M. Angew. Chem. Int. Ed. 2013, 52, 10830-10834. (d) Bahri, J.; Blieck, R.; Jamoussi, B.; Taillefer, M.; Monnier, F. Chem. Commun. 2015, 51, 11210-11212. (e) Bahri, J.; Jamoussi, B.; van Der Lee, A.; Taillefer, M.; Monnier, F. Org. Lett. 2015, 17, 1224-1227. (f) Blieck, R.; Bahri, J.; Taillefer, M.; Monnier, F. Org. Lett. 2016, 18, 1482-1485.

(4) Some of the reported protocols, however, employ amines activated with leaving groups on nitrogen in conjunction with hydride donors. For relevant examples, see ref. (3a), (3b) and (3f).

(5) The only previous example of Cu-catalyzed hydroamination of allene derivatives is the intramolecular cyclization of amine-substituted allenes: Tsuhako, A.; Oikawa, D.; Sakai, K.; Okamoto, S. Tetrahedron Lett. 2008, 49, 6529-6532.

(6) To the best of our knowledge, there is no report in the literature concerning the mechanism of this transformation. There are, however, several studies on related Au-catalyzed reactions: (a) Wang, Z. J.; Benitez, D.; Tkatchouk, E.; Goddard III, W. A.; Toste, F. D. J. Am. Chem. Soc. 2010, 132, 13064-13071. (b) Nishina, N.; Yamamoto, Y. Tetrahedron Lett. 2008, 49, 4908-4911. (c) Kovács, G.; Lledós, A.; Ujaque, G. Angew. Chem. Int. Ed. 2011, 50, 11147-11151. (d) Zhdanko, A.; Maier, M. E. Angew. Chem. Int. Ed. 2014, 53, 7760- 
(7) Hoye, T. R.; Eklov, B. M.; Ryba, T. D.; Voloshin, M.; Yao, L. J. Org. Lett. 2004, 6, 953-956.

(8) Franc, G.; Jutand, A. Dalton Trans. 2010, 39, 7873-7875.

(9) (a) Patil, R. D.; Adimurthy, S. Adv. Synth. Catal. 2011, 353, 1695-1700. (b) Patil, R. D.; Adimurthy, S. RSC Adv. 2012, 2, 5119-5122.

(10) Engelsma, G.; Havinga, E. Tetrahedron 1958, 2, 289-295.

(11) Sumalekshmy, S.; Gopidas, K. R. Chem. Phys. Lett. 2005, 413, 294-299.

(12) Jenkins, C. L.; Kochi, J. K. J. Am. Chem. Soc. 1972, 94, 843-855.

(13) The addition of molecular sieves, as described in the protocol originally reported by us (see ref. 3f), is unnecessary if rigorously dried dioxane is employed.

(14) (a) Cook, B. W.; Miller, R. G. J.; Todd, P. F. J. Organomet. Chem. 1969, 19, 421-430. (b) Solomon, R. G.; Kochi, J. K. J. Chem. Soc., Chem. Commun. 1972, 3, 559-560. (c) Salomon, R. G.; Kochi, J. K. J. Am. Chem. Soc. 1973, 95, 1889-1897. (d) Salomon, R. G.; Kochi, J. K. J. Organomet. Chem. 1974, 64, 135-143. (e) Reger, D. L.; Dukes, M. D. J. Organomet. Chem. 1976, 113, 173-185. (f) Munakata, M.; Kitagawa, S.; Kosome, S.; Asahara, A. Inorg. Chem. 1986, 25, 2622-2627. (g) Masuda, H.; Yamamoto, N.; Taga, T.; Machida, K.; Kitagawa, S.; Munakata, M. J. Organomet. Chem. 1987, 322, 121-129. (h) Baum, T. H.; Larson, C. E.; May, G. J. Organomet. Chem. 1992, 425, 189-200.

(15) Shaw, B. L.; Stringer, A. J. Inorganica Chim. Acta Rev. 1973, 7, 1-10.

(16) Vrieze, K.; Volger, H. C.; Praat, A. P. J. Organomet. Chem. 1970, 21, 467-475.

(17) (a) Salvadori, P.; Uccello-Barretta, G.; Lazzaroni, R.; Caporusso, A. M. J. Chem. Soc., Chem. Commun. 1990, 16, 1121-1123. (b) Muhs, M. A.; Weiss, F. T. J. Am. Chem. Soc. 1962, 84, 4697-4705.

(18) (a) Nagendrappa, G.; Joshi, G. C.; Devaprabhakara, D. J. Organomet. Chem. 1971, 27, 421-426. (b) Mannschreck, A.; Munninger, W.; Burgemeister, T.; Gore, J.; Cazes, B. Tetrahedron 1986, 42, 399-408.

(19) The ratio of the displacement constants $K_{\mathrm{S}}(\mathbf{1} \mathbf{a}) / K_{\mathrm{S}}(\mathbf{1 b})=30$ is of the same order of magnitude of the ratio between the dissociation constants reported in Table $2, K_{\mathrm{D}}(\mathbf{1 a}) / K_{\mathrm{D}}(\mathbf{1 b})=57$. This is to be expected, as these two constants both mirror the affinity of the allene for $\mathrm{Cu}(\mathrm{I})$.

(20) The two isomers are separable by standard flash chromatography on silica gel. This isomeric ratio is slightly diminished if less than 4.0 equiv of amine are used, e.g. it is $82: 8$ for 2.0 equiv of morpholine.

(21) Conversion of branched products similar to $\mathbf{3 a}$ to the linear isomer is known to take place with a Rh-based hydroamination catalyst in the presence of carboxylic acids, probably by the intermediacy of an $\eta^{3}$-allyl $\mathrm{Rh}(\mathrm{III})$ complex: Chen, Q.-A.; Chen, Z.; Dong, V. M. J. Am. Chem. Soc. 2015, 137, 8392-8395.

(22) Under reaction conditions, copper can have a coordination number up to 4 , as calculations for the formation of $\left[\mathrm{Cu}(\mathrm{mp})_{\mathrm{n}}\right]^{+}$point out (See the Supporting Information, section 1.4). The reaction of diethylamine and $\mathrm{CuCl}$, for instance, can give 1:1 or 2:1 complexes: (a) Clifton, J. R.; Yoke, J. T. Inorg. Chem. 1966, 5, 1630-1632. An electrochemical study demonstrated that the maximum achievable coordination number for cationic $\mathrm{Cu}(\mathrm{I}) / \mathrm{amine}$ complexes may be between 2 and 4 depending on the amine (e.g. it is 2 for piperidine and 3 for butylamine and quinoline): (b) Chen, K.-L. H.; Iwamoto, R. T. Inorganica Chim. Acta 1971, 5, 97-102. For homogeneity and in order to make meaningful comparisons, tricoordinate geometries have been assumed throughout all the calculations.

(23) (a) Normant, J. F.; Alexakis, A. Synthesis 1981, 1981, 841-870. (b) Nilsson, K.; Ullenius, C.; Krause, N. J. Am. Chem. Soc. 1996, 118, 4194-4195. (c) Basheer, A.; Marek, I. Beilstein J. Org. Chem. 2010, 6, No. 77.

(24) (a) Ess, D. H.; Houk, K. N. J. Am. Chem. Soc. 2007, 129, 10646-10647. (b) van Zeist, W.-J.; Bickelhaupt, F. M. Org. Biomol. Chem. 2010, 8, 3118-3127.

(25) Cyclic allene 1c failed to give any detectable amount of hydroamination product, probably because of the easy polymerization due to ring strain.

(26) Assignment of the resonances of $(\boldsymbol{E})-\mathbf{2} \mathbf{c}$ and $(\boldsymbol{Z})-\mathbf{2} \mathbf{c}$ was done by comparison with published spectroscopic data: Nishina, N.; Yamamoto, Y. Synlett 2007, 2007, 1767-1770.

(27) (a) Foster, J. P.; Weinhold, F. J. Am. Chem. Soc. 1980, 102, 7211-7218. (b) Reed, A. E.; Weinstock, R. B.; Weinhold, F. J. Chem. Phys. 1985, 83, 735-746.

(28) Brandsma, L. Synthesis of Acetylenes, Allenes and Cumulenes: Methods and Techniques (Best Synthetic Methods); Elsevier Ltd.: Oxford, 2003; pp 323-326.

(29) Lu, T.; Lu, Z.; Ma, Z.-X.; Zhang, Y.; Hsung, R. P. Chem. Rev. 2013, 113, 4862-4904.

(30) $\mathrm{Cu}(\mathrm{NCMe})_{4}(\mathrm{OTf})$ was selected for this screening because of its good solubility in all the solvent tested.

(31) Primary aromatic or aliphatic amines are not reactive under our conditions employing $\mathrm{Cu}(\mathrm{NCMe})_{4} \mathrm{PF}_{6}$ as a catalyst. For the gold-catalyzed hydroamination of allenamides with anilines, see: Hill, A. W.; Elsegood, M. R. J.; Kimber, M. C. J. Org. Chem. 2010, 75, 5406-5409.

(32) Carbery, D. R. Org. Biomol. Chem. 2008, 6, 3455-3460.

(33) (a) Boissier, J. R.; Combes, G.; Effler, A. H.; Klinga, K.; Schlittler, E. Experientia 1971, 27, 677. (b) Gribble, G. W.; Switzer, F. L.; Soll, R. M. J. Org. Chem. 1988, 53, 3164-3170.

(34) (a) Tsuda, M.; Kawasaki, N.; Kobayashi, J. Tetrahedron Lett. 1994, 35, 4387-4388. (b) Pouilhès, A.; DuvalLungulescu, M.; Lambel, S.; Léonce, S.; Langlois, Y. Tetrahedron Lett. 2001, 42, 8297-8299. 
(35) (a) Hughes, J. L.; Seyler, J. K. Tetrahydroisoquinoline compounds. US 3994891 A, 1976. (b) Kehler, J.; Poulsen, A.; Bjørnholm, B.; Kroll, F.; Bang, N. M. 3,4-Dihydro-1 $H$-isoquinoloin-2-yl-derivatives. WO2003051869 A1, 2003.

(36) (a) Wei, L.-L.; Xiong, H.; Douglas, C. J.; Hsung, R. P. Tetrahedron Lett. 1999, 40, 6903-6907. (b) Wei, L.-L.; Mulder, J. A.; Xiong, H.; Zificsak, C. A.; Douglas, C. J.; Hsung, R. P. Tetrahedron 2001, 57, 459-466. (c) Tracey, M. R.; Grebe, T.; Mulder, J. A.; Hsung, R. P. Org. Synth. 2005, 81, 147-157. (d) Fenández, I.; Monterde, M. I.; Plumet, J. Tetrahedron Lett. 2005, 46, 6029-6031. (e) Bousfield, T. W.; Kimber, M. C. Tetrahedron Lett. 2015, 56, 350-352. (f) Li, Y.; Chen, J.; Qiu, R.; Wang, X.; Long, J.; Zhu, L.; Au, C.-T.; Xu, X. Tetrahedron Lett. 2015, 56, 5504-5507.

(37) Even if for synthetic purposes the reaction is most efficiently carried out in THF as a solvent, NMR spectra are better resolved if dioxane is used instead, therefore this solvent has been selected for NMR kinetic studies. For consistency, all theoretical calculations have been carried out by simulating dioxane with the PCM solvation model.

(38) Although the analytical derivation of rate equations under the usual assumptions of Michaelis-Menten enzyme kinetics is feasible, several higher-order equilibria are plausible; for instance mp can form homoleptic $\mathrm{Cu}(\mathrm{mp})_{\mathrm{n}}$ species, but also $\left[(\mathbf{1 b}) \mathrm{Cu}(\mathrm{mp})_{n}\right]$ heteroleptic complexes. All the schemes involving higher-coordinate species give a qualitatively similar picture in which the rate decreases at high [mp].

(39) Hansch, C.; Leo, A.; Taft, R. W. Chem. Rev. 1991, 91, 165-195.

(40) Gaussian 09, Revision E.01, Frisch, M. J.; Trucks, G. W.; Schlegel, H. B.; Scuseria, G. E.; Robb, M. A.; Cheeseman, J. R.; Scalmani, G.; Barone, V.; Mennucci, B.; Petersson, G. A.; Nakatsuji, H.; Caricato, M.; Li, X.; Hratchian, H. P.; Izmaylov, A. F.; Bloino, J.; Zheng, G.; Sonnenberg, J. L.; Hada, M.; Ehara, M.; Toyota, K.; Fukuda, R.; Hasegawa, J.; Ishida, M.; Nakajima, T.; Honda, Y.; Kitao, O.; Nakai, H.; Vreven, T.; Montgomery, Jr., J. A.; Peralta, J. E.; Ogliaro, F.; Bearpark, M.; Heyd, J. J.; Brothers, E.; Kudin, K. N.; Staroverov, V. N.; Kobayashi, R.; Normand, J.; Raghavachari, K.; Rendell, A.; Burant, J. C.; Iyengar, S. S.; Tomasi, J.; Cossi, M.; Rega, N.; Millam, N. J.; Klene, M.; Knox, J. E.; Cross, J. B.; Bakken, V.; Adamo, C.; Jaramillo, J.; Gomperts, R.; Stratmann, R. E.; Yazyev, O.; Austin, A. J.; Cammi, R.; Pomelli, C.; Ochterski, J. W.; Martin, R. L.; Morokuma, K.; Zakrzewski, V. G.; Voth, G. A.; Salvador, P.; Dannenberg, J. J.; Dapprich, S.; Daniels, A. D.; Farkas, Ö.; Foresman, J. B.; Ortiz, J. V.; Cioslowski, J.; Fox, D. J. Gaussian, Inc., Wallingford CT., 2009.

(41) Stephens, P. J.; Devlin, F. J.; Chabalowski, C. F.; Frisch, M. J. J. Phys. Chem. 1994, 98, 11623-11627.

(42) Grimme, S.; Antony, J.; Ehrlich, S.; Krieg, H. J. Chem. Phys. 2010, 132 (15), 154104.

(43) Grimme, S.; Ehrlich, S.; Goerigk, L. J. Comput. Chem. 2011, 32, 1456-1465.

(44) (a) Hay, P. J.; Wadt, W. R. J. Chem. Phys. 1985, 82, 270-283. (b) Wadt, W. R.; Hay, P. J. J. Chem. Phys. 1985, 82, 284-298. (c) Hay, P. J.; Wadt, W. R. J. Chem. Phys. 1985, 82, 299-310.

(45) (a) Ehlers, A. W.; Böhme, M.; Dapprich, S.; Gobbi, A.; Höllwarth, A.; Jonas, V.; Köhler, K. F.; Stegmann, R.; Veldkamp, A.; Frenking, G. Chem. Phys. Lett. 1993, 208, 111-114. (b) Roy, L. E.; Hay, P. J.; Martin, R. L. J. Chem. Theory Comput. 2008, 4, 1029-1031.

(46) Check, C. E.; Faust, T. O.; Bailey, J. M.; Wright, B. J.; Gilbert, T. M.; Sunderlin, L. S. J. Phys. Chem. A 2001, $105,8111-8116$.

(47) (a) Tomasi, J.; Mennucci, B.; Cammi, R. Chem. Rev. 2005, 105, 2999-3094. (b) Cossi, M.; Scalmani, G.; Rega, N.; Barone, V. J. Chem. Phys. 2002, 117, 43-54.

(48) Ordinary flash-chromatography grade silica gel was slurried with about twice its volume of an aqueous $\mathrm{NaHCO}_{3}$ solution (approx. $50 \mathrm{~g} / \mathrm{L}$ ), washed with water on a Buchner funnel, then with acetone and dried in high vacuum overnight at $140{ }^{\circ} \mathrm{C}$. Some grades of commercial silica gel caused decomposition of these acidsensitive products if this treatment was omitted. See also ref. (36c), note 8. 
1

2

3

4

5

6

7

8

9

10

11

12

13

14

15

16

17

18

19

20

21

22

23

24

25

26

27

28

29

30

31

32

33

34

35

36

37

38

39

40

41

42

43

44

45

46

47

48

49

50

51

52

53

54

55

56

57

58

59

60

\section{TOC graphics}

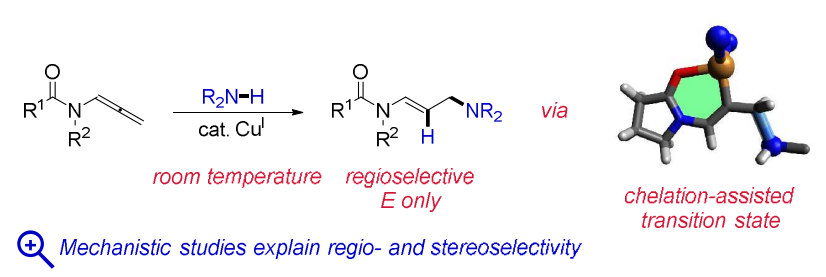

